\title{
Factors Related to Adherence with Treatment of Dyslipidemic Patients on Continuous Use of Oral Lipid-Lowering Drugs
}

\author{
Ana Paula Zambuzi Cardoso Marsola, Evandro José Cesarino \\ School of Pharmaceutical Sciences of Ribeirão Preto, University of São Paulo, Ribeirão Preto, Brazil \\ Email: ana.paula.cardoso@usp.br
}

Received 10 May 2014; revised 22 June 2014; accepted 8 July 2014

Copyright (C) 2014 by authors and Scientific Research Publishing Inc.

This work is licensed under the Creative Commons Attribution International License (CC BY). http://creativecommons.org/licenses/by/4.0/

(c) () Open Access

\begin{abstract}
Several studies have shown that regular prescribed statins may reduce cardiovascular events and decrease the overall mortality. The aim of this study was to analyze factors related to medication and patients with dyslipidemia, statin users in the city of Ribeirão Preto, São Paulo, Brazil. It was an observational, descriptive, traverse character, relating to the year 2007 . We included 332 individuals, randomly selected, of both sexes, referred to public health system and private clinics. The selected individuals were submitted to an interview and their medical files analyzed. Simvastatin was the most frequently used oral lipid-lowering drugs. $60 \%$ of patients showed forgetfulness as the main cause for treatment interruption, followed by the difficulty of finding of drugs in public pharmacies. Adherence to diet was the main conduct adopted by patients to help control lipid levels. The prevalent adverse events were muscle cramps, paresthesias of the limbs and muscle pains. Among the key factors that would discourage the correct follow-up treatment for lipid control were: long wait for office visits and the difficulties of finding of drugs in pharmacies (Clinical Hospital of the Faculty of Medicine of Ribeirão Preto-USP and public health posts). The study allowed a reflection regarding the functioning of the Public Health System. The study allows a reflection regarding the functioning of the Public Health System for which we must constantly search for strategies that enable the same functionality, which has factors that discourage patient adherence to treatment.
\end{abstract}

\section{Keywords}

Dyslipidemias, HMG-CoA Reductase Inhibitors, Cardiovascular Diseases 


\section{Introduction}

The prevalence of cardiovascular disease (CVD) varies according to the Brazilian regions. In the South and South East, for example, a higher percentage of CVD deaths, 33.5\% and 34.9\% respectively was observed. In the 60 s tripled the number of causa mortis by circulatory system diseases (CSD) in Brazil, reaching $32 \%$ in 1999 [1]. This increase in the number of cases is related to the high prevalence of modifiable risk factors and treatable for atherosclerosis, such as dyslipidemia [2]. According data from the Brazilian Society of Cardiology (BSC), $40 \%$ of Brazilians have TC $\geq 200 \mathrm{mg} / \mathrm{dl}$ and $13 \%$ had TC $\geq 240 \mathrm{mg} / \mathrm{dl}$ [3]. Atherosclerosis is defined to a chronic inflammatory disease dependent on several factors consequent of a response to endothelial aggression, affecting arteries of medium and large caliber. Research demonstrates that cellular and molecular components of the development and progression of atherosclerosis is a dynamic and modifiable inflammatory process [4]. The statins are HMG-CoA reductase inhibitors, key enzyme in the cholesterol synthesis by acting on its control and increasing the expression of high density lipoprotein receptors on the surface of the liver [5]. Thus, there is less synthesis and clearance of VLDL and LDL by the liver. After discovery and development of statins, shortly several studies have been published during the 90s demonstrating that statins could reduce heart diseases death and heart attacks by $20 \%-50 \%$, depending on the level of blood cholesterol and the presence or absence of other risk factors for CVD [6]. Statins act in the lipid profile in different ways, such as: inhibiting the proliferation of smooth muscle cells and migration by growth factors which influence the stability of the atheromatous plaque and atherothrombosis; improving endothelial function and increasing the availability of nitric oxide, interfering with the pathologic process of atherosclerosis [7]. The lipid lowering has several characteristics that make them drugs that require special care by health professionals, both in clinic and in the dispensation of drugs and care offered to patients who use them. Several adverse reactions have been reported present in package insert or not, and lipid-lowering drugs that make the special attention. The attainment of these drugs in public health does not happen easily and continuously. There is the need for special authorizations from the Pharmacies of Exceptional Drug Program of Brazilian government, which causes various disorders to patients during the treatment of dyslipidemia. The direct and indirect consequences of dyslipidemias undiagnosed or poorly controlled entail unemployment, physical and working disability, medical and hospital costs and early retirement. These socioeconomic impacts need to be analyzed as well, because they give the substrate for making administrative and policies decisions in the public health. The objective of this study was to analyze factors related to drugs and patient with dyslipidemia, statin users in the city of Ribeirão Preto, São Paulo, Brazil, assessing treatment adherence and related factors, like the availability of lipid lowering in the public health and the negative impact that the absence of drugs may trigger in the treatment of dyspidemias.

\section{Material and Methods}

The casuistic was composed of individuals living in Ribeirão Preto, São Paulo, Brazil, who used statins in 2007, being dispensed in the Exceptional Drug Program distributed by the Ministry of Health, Outpatient Pharmacy of Clinical Hospital of Faculty of Medicine of Ribeirão Preto-USP (HCFMRP-USP). These individuals were identified through the Exceptional Drug List of Outpatient Pharmacy and were personally interviewed to obtain data related to medication and patient, compiled in an epidemiological data sheet. These data sheet was based on pre-manufactured instruments with data of interest for this study including subjective questions involving responses and personal opinions. It was an observational, descriptive, traverse character, relating to the year 2007. We included 332 individuals, 310 were submitted to an interview and it was found 22 deaths. The subjects were randomly selected, of both sexes, forwarded by public health system and private clinics. All medical files of the subjects were analyzed. The criteria for the inclusion and exclusion of patients were the same conditioning the supply of special drugs by the Health Department of the State of São Paulo and the Brazilian Ministry of Health for patients with disorders of lipoprotein metabolism (Table 1).

Subjects were only included in the study after signing the Instrument of Consent information, read together with the patient, answered any questions about this work and delivered a copy of the term of equal content. The research project had the approval of the Research Ethics Committee of HCFMRP-USP. The statistical analysis consisted of the calculation of descriptive statistics such as mean, median, minimum and maximum values, and standard deviations for the variables studied. The structure of the databases was performed using Epi Info version 6.04 program for detailed analysis of data and eventually through the Excel 2003 Program for simpler analysis. 
Table 1. Inclusion and exclusion criteria of the study.

- Post-AMI patients with LDL $>100 \mathrm{mg} / \mathrm{dL}$.

- $\quad$ Patients with LDL cholesterol $>130 \mathrm{mg} / \mathrm{dL}$ after 3 months of non-pharmacological treatment and at least one of the following conditions: HDI proven by ET or MS, previous AMI , previous myocardial revascularization or coronary angiography with greater than $30 \%$ obstruction lesions; atherosclerotic disease in other arterial beds: peripheral vascular disease with intermittent claudication or obstruction greater than $50 \%$ doppler, abdominal aortic aneurysm and/or symptomatic carotid disease; DM; genetic syndromes: familiar hypercholesterolemia and familiar combined hyperlipidemia; absolute Framingham score high ( $\geq 9$ points for men and $\geq 15$ points for women).

- Patients with LDL > $160 \mathrm{mg} / \mathrm{dL}$ cholesterol after 6 months of non-pharmacological treatment and at least one of the following conditions: absolute Framingham score high ( $\geq 6$ points for men and for women $\geq 10$ points); at least 2 of the following factors: age $>55$ years, Hypertension, HDL $<40 \mathrm{mg} / \mathrm{dL}$, smoking (in the presence of mental retardation or severe psychiatric disorder only).
- $\quad$ Pregnant or situations where pregnancy can not be avoided;

- Lactation;

- $\quad$ Active or chronic liver disease;

- Persistent elevation of transaminases;

- A history of hypersensitivity to statins and fibrates;

- Myositis or polymyositis;

- Proven inability to adherence to exercise programs, except for cases of physical or mental disability;

- Neoplasms or terminal illness with less than two years estimated survival;

Untreated hypothyroidism;

- Alcohol use or abuse of drugs present;

- Continuity of smoking

AMI: Acute Myocardial Infarction; HDI: Heart Disease Ischaemic; TE: Exercise Testing; MS: Myocardial Scintigraphy; DM: Diabetes Mellitus.

\section{Results}

The age range of patients analyzed varied from 15 to 89 years $(X=62 \pm 12.35$, median $=63)$. There was a prevalence of caucasians (66.7\%), then brown/mulatto (19.20\%), black (12.30\%), yellow/oriental (1.4\%) and indigenous (0.5\%) which is consistent with the ethnic constitution of the population [8]. Concerning the level of education of the study population, 131 individuals $(47.8 \%)$ reported having never attended school or have finished high school and 66 individuals (24.1\%) reported having completed elementary school.

There was a predominance of patients using simvastatin (39\%) compared to atorvastatin (34\%), after analysis of 310 patients. We analyzed data from 199 patients regarding adherence to treatment, as shown in Table 2.

The study shows that over half of the patients reported having interrupted treatment at some time in 2007 for forgetfulness, the second reason given was the difficulty (of lack thereof) to finding the drugs from pharmacies the public health system in Brazil (41.17\%) that distribute lipid lowering in the Brazilian public health system (Table 2). Table 3 was analyzed data from 224 individuals in regard to prevalent adverse effects in patients who used statins during the period examined in the study.

Therefore, it was found in this study, the adverse reactions reported by all groups of statins were similar and consistent with the reactions described in the literature. Moreover, reactions related to muscle problems and paresthesias (tingling/cold/heat) of limbs were the most prevalent complaints among the study patients. Concerning the guidelines utilized by patients to help control cholesterol levels, 279 individuals responded to questions about this behavior, were analyzed and it appeared that patients were more adept at diets and diets concomitant physical exercise showing a percentage of $31 \%$ in both questions, but the percentage of patients that do not perform any practice for aid to treatment was also high, 23\%, as explained in Figure 1.

Patients were asked about the performing medical management in other parallel to the public system Brazilian health institutions, such as covenants or private clinics and among the 310 patients interviewed, $13.5 \%$ reported some other medical segments not associated with the public system Brazilian health. Among 219 patients analyzed, $14.6 \%$ reported having no knowledge about the cardiovascular complications that no control of cholesterol levels leads to health and $16 \%$ reported having difficulty understanding the way that physicians or other health professionals advise on the treatment or control of cholesterol. Concerning the factors that would discourage the correct follow-up treatment for lipid control, the most relevant factors identified by patients can be observed in Table 3.

The data in Table 4 show that the waiting time for both office visits as to the finding of medicines in pharmacies are the most relevant factors described by patients that could discourage them to correctly follow the treatment of dyslipidemia. 
Table 2. Descriptive analysis of reasons for interruption of drug therapy lipid control relating to 199 Brazilian adults dyslipidemic patients*.

\begin{tabular}{cc}
\hline Forgetfulness & \% \\
\hline Lack of drugs in pharmacies in the public health system & 59.8 \\
To think that do not need drugs (not observed improvement) & 41.17 \\
To present strange drug reactions & 7.84 \\
Have taking them several times a day & 5.88 \\
To feel worse when taking the drugs & 5.88 \\
Further reasons & 3.92 \\
\hline
\end{tabular}

* Data collected in 2007.

Table 3. Descriptive analysis of main adverse drug reactions of drug therapy lipid control relating to 224 Brazilian adults dyslipidemic patients* .

\begin{tabular}{cccc|}
\hline \multicolumn{2}{|c}{ Atorvastatin $^{\mathbf{a}}$} & \multicolumn{2}{c|}{ Simvastatin $^{\mathbf{b}}$} \\
\hline & Occurrence (\%) & & Occurrence (\%) \\
\hline Paresthesias of limbs & 37.5 & Muscle cramps & 45.0 \\
Muscle aches & 31.7 & Muscle aches & 39.1 \\
Muscle cramps & 30.7 & Weakness & 39.1 \\
Sleeplessness & 27.8 & Paresthesias of limbs & 37.5 \\
Weakness & 25.0 & Sleeplessness & 29.1 \\
\hline
\end{tabular}

${ }^{*}$ Data collected in 2007; ${ }^{\mathrm{a}} n=104 ;{ }^{\mathrm{b}} n=120$.

Table 4. Descriptive analysis of discouraging factors for the correct treatment of therapy lipid control relating to 219 Brazilian adults dyslipidemic patients*.

\begin{tabular}{cc}
\hline \multicolumn{1}{c}{ Factors } & $\%$ \\
\hline Long time to be served in office visits & 23.74 \\
Long waiting time to be served in pharmacy to finding the drugs & 19.63 \\
Distance from home to the pharmacy & 15.98 \\
Transportation from home to the pharmacy & 12.32 \\
The way of attendance in the pharmacy & 9.58 \\
Other factors & 2.73
\end{tabular}

${ }^{*}$ Data collected in 2007. $n=219$.

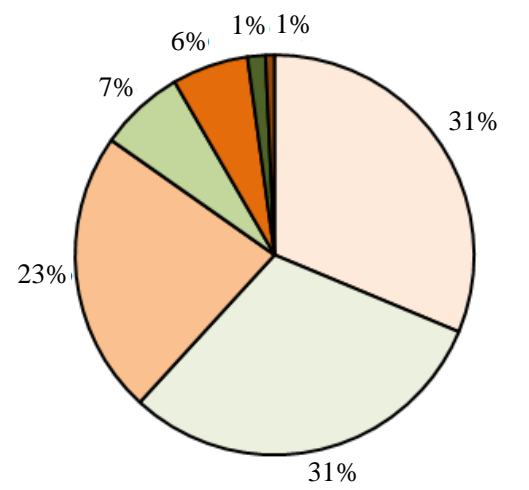
口Diets
$\square$ Diets and physical exercises
$\square$ No practices
$\square$ Physical exercises
$\square$ Diets, physical exercises and natural products

Figure 1. Practices adopted by patients to aid in drug therapy. 


\section{Discussion}

The limitation of the study is in the fact that not all patients wanted or could answer all the questions of the questionnaire used, so the number of patient responses varied depending on each question or topic.

Noted the prevalence of low adherence to physical activity. It is widely known that regular physical activity, avoiding a sedentary lifestyle increases the levels of HDL-C, lowers triglycerides and LDL-C. Furthermore, there is optimization of postprandial lipoprotein clearance and favorable effects on lipoprotein enzyme activity [9]. A study revealed that statin therapy associated with diet and physical activity in moderately hyperlipidemic patients without prior history of CVD, is of great benefit in preventing cardiovascular events, but not proves benefits in preventing total causa mortis [10]. This study there was the prevalence of adverse events related to muscle problems and paresthesias in the limbs, which is compatible with many studies in the literature, as well as a higher incidence of adverse reactions in the atorvastatin group. Study of the American College of Cardiology and the American Heart Association on the use and safety of statins, defined four syndromes: myopathy (muscle any complaint regarding statins), myalgia (muscle complaints without elevation of serum CPK), myositis (muscle complaint with elevation CPK) and rhabdomyolysis (markedly elevated CPK levels, typically $>10$ times the upper level associated with elevated levels of creatinine [11]. Unfortunately still a large part of the Brazilian population is not treated according to the guidelines on dyslipidemia to CVD prevention which usually reflect the results of clinical trials and best recommendations for increased benefits the population. The determination of the effectiveness of treatments and procedures is of fundamental importance because economic resources are limited and thus the social priorities should be set. We cannot dissociate our actions of the socioeconomic context of patients and the system where we are inserted. The prevalence of the use of simvastatin is due to its low cost and the preference prescribing of this drug by physicians. We notice that there is a low adherence to treatment, justified by forgetfulness and difficulty of getting the drug. This is relevant to health professionals must rethink the assistance provided, as the difficulty in understanding the guidance provided was appointed. The study offered a reflection on the functioning of the Brazilian health public system for which we must constantly seek strategies that enable its functionality, which presents factors that discourage adherence to treatment. Access to drugs is a determining factor in the fulfillment of the prescribed treatment. The lack of access to drugs may lead to clinical decompensation and increased spending on secondary and tertiary care [12]. The universalization of health, despite being a historic advance in social policy in Brazil, provides an overload of demand major impact on the organization of services. There is a growing amount of need not accompanied by equivalent financial support, which creates consequences at the time of provision of some services [13].

\section{Conclusion}

To sum up, among the statins, simvastatin is the prevalent drug; this is probably due to their low cost and preferably from prescription by physicians. We notice that there is a low adherence to treatment, justified by forgetfulness and difficulty of finding drugs. These data are important because health professionals should rethink the assistance provided, because the difficulty of understanding the guidelines provided was appointed. This study allowed a reflection on the functioning of the health system to which we must constantly seek strategies that enable its functionality, which has factors that discourage adherence of treatment.

\section{Acknowledgements}

Professionals and patients of the Clinical Hospital of the Faculty of Medicine of Ribeirão Preto-USP-HCFMRP, thanks CNPq and CAPES for financial support.

\section{References}

[1] Brasil, Ministério da Saúde, Secretaria Executiva (2002) A Saúde no Brasil: Estatísticas Essenciais. Estatística e Informação para Saúde, 22, 1990-2000.

[2] Fonseca, F.A.H. and Follador, W. (2003) Farmacoeconomia e as Vastatinas na Doença Cardiovascular. Revista Brasileira de Medicina, 60, 357-363.

[3] Martinez, T.L.R., et al. (2003) Campanha Nacional de Alerta Sobre o Colesterol Elevado. Determinação do Nível de Colesterol de 81.262 Brasileiros. Arquivos Brasileiros de Cardiologia, 80, 635-638. http://dx.doi.org/10.1590/S0066-782X2003000600006 
[4] Martinez, T.L.R. (2003) Manual de Condutas Clínicas em Dislipidemias. Medline Editora, Rio de Janeiro, 35.

[5] Vaughan, C.J., Murphy, M.B. and Buckley, B.M. (1996) Statins Do More than Just Lower Cholesterol. The Lancet, 348, 1079-1082. http://dx.doi.org/10.1016/S0140-6736(96)05190-2

[6] Freeman, W.M. (2006) Statins, Cholesterol, and the Prevention of Coronary Heart Disease. The Federation of American Societies for Experimental Biology Journal, 20, 200-201. http://dx.doi.org/10.1096/fj.06-0202ufm

[7] Mennickent, S.C., et al. (2008) Efectos Pleiotrópicos de las Estatinas. Revista Médica del Chile, 136, 775-782.

[8] Instituto Brasileiro de Geografia e Estatística (IBGE). http://www.ibge.gov.br/home/estatistica/populacao/condicaodevida/indicadoresminimos/sinteseindicsociais2006/indic _sociais2006.pdf

[9] Xavier, H.T. (2004) Manual de Dislipidemias e Cardiometabolismo, Ed. BBS, São Paulo, 215.

[10] Bukkapatnam, R.N., Gabler, N.B. and Lewis, W.R. (2004) Statins for Primary Prevention of Cardiovascular Mortality in Women: A Systematic Review and Meta-Analysis. Preventive Cardiology, 13, 84-90. http://dx.doi.org/10.1111/j.1751-7141.2009.00059.x

[11] Pasternak, R.C., et al. (2002) ACC/AHA/NHLBI Clinical Advisory on the Use and Safety of Statins. Journal of the American College of Cardiology, 40, 567-572. http://dx.doi.org/10.1016/S0735-1097(02)02030-2

[12] Paniz, V.M.V., et al. (2008) Acesso a Medicamentos de uso Contínuo em Adultos e Idosos nas Regiões Sul e Nordeste do Brasil. Caderno de Saúde Pública, 24, 267-680.

[13] Aziz, M.M., et al. (2011) Prevalência e Fatores Associados ao Acesso a Medicamentos pela População Idosa em uma Capital do sul do Brasil: Um Estudo de Base Populacional. Caderno de Saúde Pública, 27, 1939-1950. 
Scientific Research Publishing (SCIRP) is one of the largest Open Access journal publishers. It is currently publishing more than 200 open access, online, peer-reviewed journals covering a wide range of academic disciplines. SCIRP serves the worldwide academic communities and contributes to the progress and application of science with its publication.

Other selected journals from SCIRP are listed as below. Submit your manuscript to us via either submit@scirp.org or Online Submission Portal.
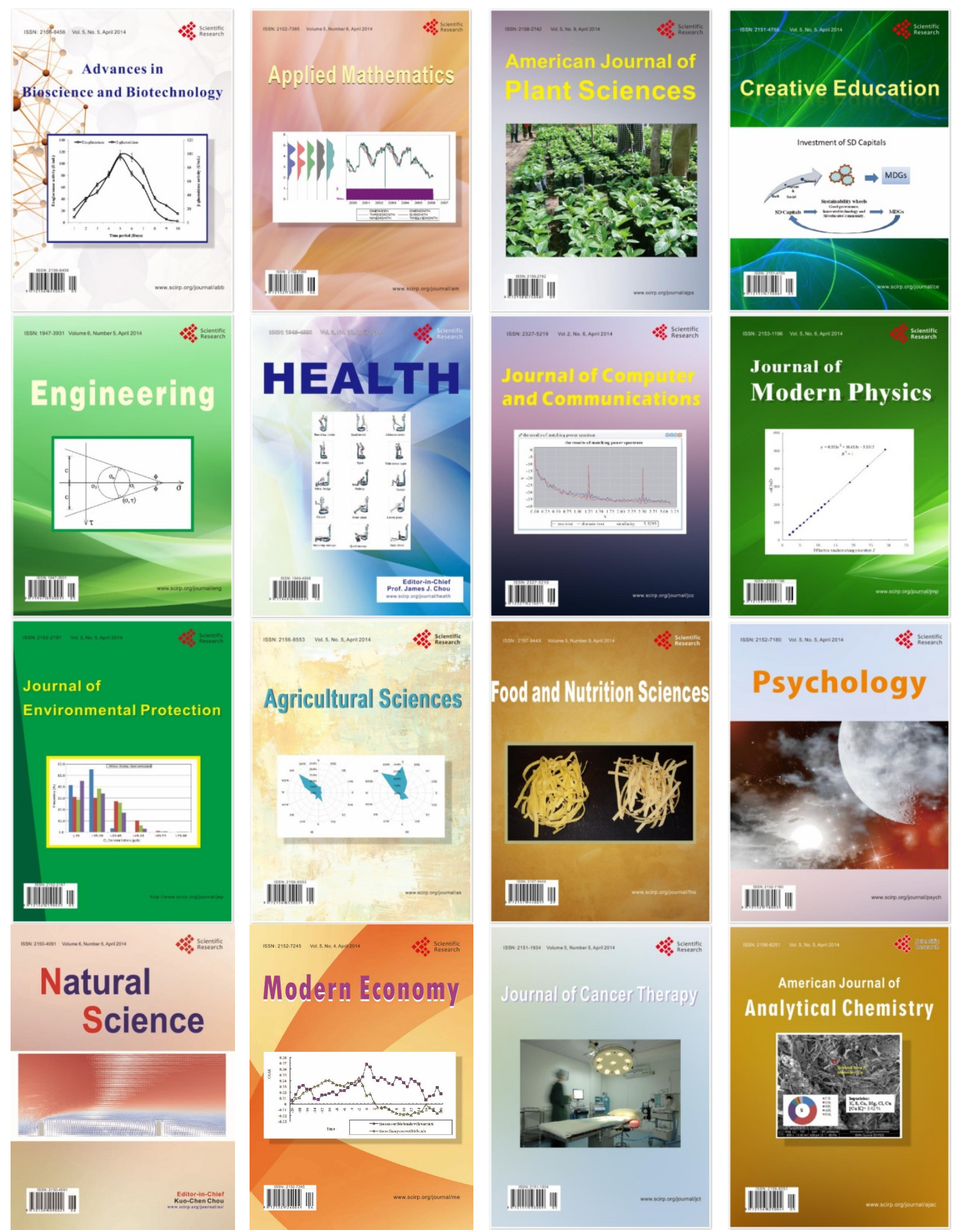